\title{
PRODUTOS MIDIÁTICO-DIGITAIS E MOLDURAS DE INTERAÇÃO: O EMOLDURAMENTO DA NOÇÃO PARTICIPAÇ̃̃O E CIDADANIA DESDE AS MÍDIAS PRIVADAS
}

\author{
DIGITAL-MEDIA PRODUCTS AND MOLDINGS INTERACTION: THE FRAMING OF \\ THE NOTION OF PARTICIPATION AND CITIZENSHIP FROM THE PRIVATE MEDIA.
}

\author{
PRODUCTOS DE MEDIOS DIGITALES Y MOLDURAS DE INTERACCIÓN: \\ ENMARCADO DE LA NOCIÓN DE PARTICIPACIÓN Y CIUDADANÍA DESDE \\ LOS MEDIOS PRIVADOS.
}

Norberto Kuhn Júnior Doutor, PPG Diversidade cultural e inclusão social - Universidade FEEVALE nkjunior@feevale.br

Everton Rodrigo Santos Doutor, PPG Diversidade cultural e inclusão social - Universidade FEEVALE evertons@feevale.br

\begin{abstract}
Resumo
O presente estudo tem lugar no contexto dos esforços interpretativos das transformações sociomidiáticas que marcam as sociedades contemporâneas associadas às transformações nos processos de intervenção social na vida das cidades. Especificamente, buscamos analisar as novas formas de participação social na composição das políticas públicas mediante seu emolduramento em ambientes midiático-digitais, com especial atenção às estratégias de significação adotadas por empresas privadas de comunicação, que disponibilizam produtos midiáticos em torno do conceito de Participação e Cidadania. Como demarcação empírica dessa proposta de estudo estamos considerando a maior empresa jornalística atuante no polo industrial do Vale do Rio dos Sinos, no Rio Grande do Sul, o Grupo Editorial Sinos, através do seu Jornal NH em sua versão digital.
\end{abstract}

Palavras-chave: Mídias digitais. Cidadania. Interação.

\begin{abstract}
This study is placed within the context of interpretive efforts of social-media transformations that characterize contemporary societies associated with changes in the processes of social intervention in the life of cities. We specifically analyze the new forms of social participation in the composition of public policy by its framers in digital-media environments, with special attention to the significance of strategies adopted by private communication, media products that are offered around the concept of Participation and Citizenship. As an empirical demarcation study of this proposal we are considering the larger journalistic company active in the industrial center of Vale do Rio dos Sinos, at Rio Grande do Sul, the Editorial Sinos Group, through its newspaper NH in its digital version.
\end{abstract}

Keywords: Digital Medias. Citzenship. Interaction. 


\section{Resumen}

Este estudio se lleva a cabo en el contexto de los esfuerzos interpretativos sociomidiáticos de las transformaciones que caracterizan a las sociedades contemporáneas, considerando los cambios en los procesos de intervención social en la vida de las ciudades. Se busca analisar las nuevas formas de participacion social en la composición de las políticas públicas frente a su enmarcamiento en ambientes midiáticos-digitales, con atención especial a las estratégias de significación adoptadas por las empresas privadas de comunicación, que diponibilizan produtos midiáticos relacionados al concepto de Participación y Ciudadania. Como demarcación empírica de esta propuesta de estudio estamos considerando la compañía más grande activo en el centro industrial Vale do Rio do Sinos, la empresa de comunicación Grupo Editorial Sinos, a través de la versión digital de su periódico Jornal NH.

Palabras clave: Mídias-digitales. Ciudadania. Interación.

\section{INTRODUÇÃO ${ }^{1}$}

Buscamos estudar como os modos de organizar a vida das cidades $^{2}$ podem estar associados à operações de significação e interações sociais realizadas no âmbito das mediações comunicacionais - modos de ser que denominamos, a partir de Kilpp (2003), de ethicidades comunicacionais: vemos hoje a conformação de uma sociedade cuja condição reflexiva (GIDDENS, 1991) está, mais do que nunca, pautada pela intensificação e extensividade de processos de ordem midiática ${ }^{3}$. Desse modo, entendemos que estes processos midiáticos assumem papel preponderante no âmbito das comunidades locais, passando a ocupar centralidade na função interpretativa, disciplinadora e ordenadora desses ambientes sociais.

Nesse contexto teórico, nosso propósito é desenvolver uma análise interna dos processos de realização de produtos midiático-digitais desenvolvidos por empresas privadas

\footnotetext{
${ }^{1}$ Artigo debatido no XIII Congresso Internacional IBERCOM: comunicacion, cultura e esferas de poder, entre os dias 29 e 31 de maio de 2013 na Fac. CC. Da Comunicacion em Santiago de Compostela. O desenvolvimento da pesquisa contou com a bolsista do Programa de Iniciação Científica da Universidade Feevale. PIBIC-Feevale Poliana Soares acadêmica do curso de Letras - Português e Inglês da Universidade FEEVALE. Email: polianas@feevale.br. Lattes: http://lattes.cnpq.br/1521833791275464.

2 Situamos esse estudo no contexto das novas demandas que vem sendo pautadas pelos marcos jurídicos e mecanismos de planejamento e gestão dos espaços urbanos, o Plano Diretor Municipal (PDM). A partir dos anos 2000, emergem novos temas como a geração de renda de comunidades carentes, controle da violência, bem como demandas de verticalização dos mecanismos de controle e participação política; a própria gestão e definição de políticas públicas de atendimento às demandas básicas da população, de acordo com o Estatuto da Cidade, Lei 10.257, deve passar a envolver a participação dos cidadãos. (ULTRAMARI; REZENDE, 2008).

${ }^{3}$ Essa nova modalidade de interação e reprodução social tem como fundo, a vinculação genética das tecnologias comunicacionais com os modos de produção da vida material e simbólica do capitalismo contemporâneo, isto é, está necessariamente impregnada das formas culturais e dos paradigmas que são próprios do capitalismo global. Isso é o que Castells (1999) denomina de capitalismo informacional, bem como o que Giddens (1991) chama de reflexividade institucional, ou seja, uso sistemático da informação para reprodução de um sistema social.
} 
de comunicação, focando as estratégias de significação adotadas através dos emolduramentos de diferentes ambientes de significação. Voltamos nosso olhar para os produtos-ambientes fundados em torno das noções de Participação e Cidadania, que são conformadores de um ethos midiático que potencialmente incidem sobre a política local, sobre a vida da cidade; metodologicamente, realizamos esse estudo aplicando a noção de "Molduras de Interação" como conceito analisador-descritor - o que nos permitiu a tipificação da totalidade dos jornais online ativos em 2012 no RS e a composição de uma ilustração analítica a partir do estudo de caso do Jornal NH.

Conduzimos essa pesquisa direcionando o foco da análise no efeito de intrusão (BOURDIEU, 1997) das mídias privadas na vida pública das cidades, ou seja, focamos os modos como determinados produtos midiáticos, desenvolvidos pelas mídias privadas, vêm sendo associados aos processos de participação da comunidade tendo como alvo a sua cidade. Para isso, tratamos de verificar empiricamente que tipos de espaços de participação (das vivências individuais e coletivas) são gerados pelos sujeitos mediante os acionamentos/acessos (usos e apropriações) de produtos-ambientes midiáticos. Em qualquer uma dessas dimensões, da esfera pública aos produtos gerados pelas mídias privadas, entendemos que se processa a geração de um efeito de participação fundado nos domínios do que aqui denominamos de ágora eletrônica.

\section{O CONTEXTO TEÓRICO: A ÁGORA ELETRÔNICA E O FENÔMENO DE INTRUSÃO DA MÍDIA NA PRODUÇÃo DE BENS SIMBÓLICOS}

Nesse contexto de intensa urbanização ${ }^{4}$, as cidades estão transformadas em nódulos dos fluxos e influxos econômicos, legais, culturais que compõe a rede globalizada de múltiplas relações (IANNI, 2002; CASTELLS,1999); as cidades cada vez mais precisam ser cidades pensadas, submetidas a uma reflexividade social (GIDDENS, 1991) 5 .

\footnotetext{
${ }^{4}$ Atualmente, segundo documento do Ministério das Cidades (2009), as cidades brasileiras abrigam $82 \%$ da população Brasileira. Nessa atual condição, os problemas relacionados à grande cidade terão íntima relação com a chamada questão social no Brasil (RAICHELIS, 2006), envolvendo desde questões infraestruturais, de mobilidade, de saneamento básico, questões socioambientais, de moradia, de serviços e equipamentos públicos, até questões simbólicas relativas ao pertencimento, aos direitos sociais nos espaços públicos, às afirmações identitárias, e à inclusão social; todos esses assuntos passam a ocupar lugar nas pautas dos gestores públicos e de setores organizados da sociedade civil.

${ }^{5}$ As tecnicidades comunicacionais passam a desempenhar papel chave na direção de uma reflexividade social: as mídias e seus múltiplos dispositivos, cada vez mais, passam a ser entendidas como grandes coletivos de mediação (hermenêuticos), (BAUMANN, 2001; 2004) e (CANCLINI, 1999) que, ideologicamente, colocam em circulação significados e entendimentos da realidade (SILVERTONE, 2002); são, nestes termos, agentes culturais que operam como força configuradora da realidade, sendo constitutivos genéticos da sociabilidade
} 
Entendemos que essa reflexividade social estende-se em amplas redes sociais, onde as tecnologias informacionais e comunicacionais adquirem relevo como força dinamizadora da sociedade. Nesses termos, objetivamente, ganham forças as ações de informatização da gestão pública e as políticas públicas de controle social através de portais da transparência ${ }^{6}$.

Ao lado das tecnologias informacionais, que vêm compondo o aparato de controle social do estado, as diferentes mídias vêm participando no "trabalho coletivo" discursivo de produção de bens simbólicos ${ }^{7}$ e, portanto, ocupando lugar decisivo na conformação das políticas de realização da vida social. Daí resulta o fenômeno de intrusão da mídia nos diferentes campos sociais, econômico, cultural e político fundado em um novo princípio de legitimidade na produção do mundo da vida que é a visibilidade na mídia. Para Bourdieu (1996), ao estudar os efeitos de intrusão da mídia, de todos os campos de produção cultural, o campo midiático é o que está estruturalmente mais sujeito às restrições externas, mas será, também, o campo que mais intensamente irá reforçar a posição dos agentes e instituições em outros campos que estejam situados na proximidade do polo mais sujeito aos efeitos do número e do mercado ${ }^{8}$ Sob esta perspectiva de concessão à lógica comercial, um novo princípio de legitimidade na produção dos bens culturais (e simbólicos) assume relevância que é a visibilidade na mídia.

Sob o efeito desta lógica da "visibilidade" na mídia, o próprio campo midiático, como campo de produção simbólica, redimensiona uma das propriedades das trocas simbólicas que é a da produção, reprodução e acumulação de capital simbólico, ou seja, o seu capital não se

contemporânea onde tecno-inter-agimos. Desse entendimento derivam as noções de "Príncipe Eletrônico" (IANNI, 2001), e o "Olho Eletrônico (LYON, 1995).

${ }^{6}$ As modalidades de governos eletrônicos (e-GOV) são exemplos de dinamização social mediado pelo emprego das tecnologias da informação e comunicação (TIC's). Iniciado no Brasil no ano de 2000, tais programas têm como objetivo facilitar o acesso dos cidadãos às informações referentes às políticas públicas, assim como melhorar a qualidade dos serviços e informações prestados pelas mesmas seja em nível municipal, estadual ou federal. No domínio das Políticas públicas de controle social, foram criadas as Páginas de Transparência Pública; regulamentadas pelo Decreto $\mathrm{n}^{\circ} 5.482$, de 30 de junho de 2005 e pela Portaria Interministerial $\mathrm{n}^{\circ} 140$, de 16 de março de 2006. (GOVERNO FEDERAL, 2012). Sobre esse tema, destacamos ainda os estudos de Vaz (2007) e Panerai (2009).

${ }^{7}$ Os sentidos são discursivamente transportados pelos símbolos como resultantes de construções sociais que se produzem e se reproduzem, seja, conforme BOURDIEU (1996), a partir de estruturas objetivas como habitus, (das disposições razoáveis, que orientam as nossas ações), seja, conforme VERÓN (1975), a partir um sistema social de produção discursiva de natureza sempre social, portanto ideológica: neste caso o sentido é construído socialmente e a ideologia é parte integrante dessa construção.

8 "Assim, o reforço da influência de um campo jornalístico, ele próprio cada vez mais sujeito à dominação direta ou indireta da lógica comercial, tende a ameaçar a autonomia dos diferentes campos de produção cultural, reforçando, no interior de cada um deles, os agentes ou as empresas que estão mais propensos a ceder à sedução dos lucros externos porque são menos ricos em capital específico (científico, literário) e estão menos seguros dos lucros específicos que o campo the garante imediatamente ou em prazo mais ou menos longo" (BOURDIEU, Sobre a Televisão, 1997, p.110). 
realiza apenas na lógica de produção e circulação de bens e produtos midiáticos “em si”, tais como notícias, novelas, programas de auditórios, etc., mas, igualmente se realiza na sua capacidade de "capitalizar" (através desses bens e produtos), bens e produtos produzidos em outros campos (cultural, econômico e político) ${ }^{9}$. Daí então o nosso interesse em pensar as implicações dos fatores de ordem comunicacional - os efeitos de intrusão - do jornalismo online sobre os arranjos sociais locais, especialmente sobre os modos como o ato político da participação dos cidadãos - ato instaurado midiaticamente através de suas molduras - afetam a organização da vida das cidades e a gestão das cidades.

Pensar tal ordem de ethicidades, que decorre da presença dos meios de comunicação incorporada à vida social, evidenciando empiricamente os modos de sua incidência (repercussões) nos âmbitos dos usos e apropriações de dispositivos midiáticos, parece ser condição para o estudo das configurações contemporâneas de participação na vida das cidades, especialmente no âmbito das políticas públicas. Assim, ao focarmos as tecnicidades midiáticas como espaço dinamizador de participação social na vida da cidade, nos perguntamos: que tipos de molduras e moldurações, constituidoras de espaços de interações sociais midiático digitais, se estabelecem como fonte dinamizadora de participação social na vida da cidade?

\section{O CONTEXTO METODOLÓGICO: AS MOLDURAS DE PARTICIPAÇÃO COMO DESCRITOR-ANALISADOR}

Partimos do entendimento de que um jornal online, como dispositivo midiático-digital (KUHN JUNIOR, 2008), compõe-se de molduras específicas demarcadoras de "usos": tais delimitadores garantem acesso e acionam interfaces de interações entre o usuário-leitor e o jornal e, pelo efeito de intrusão, a interação estende-se para outros campos (esfera pública, por exemplo), que fazem do jornal espaço ativo de cidadania (demarcadores/geradores de espaço de realização da participação cidadã), atualizando a "ágora" como espaço de debate de temas de ordem pública.

Por moldura, como categoria descritiva, entendemos ser o demarcador de espaços de significação (cuja materialidade assume no interior dos dispositivos midiático digitais variadas formas, texturas, volume, cores, movimentos, sonoridades) que instauram e demarcam o espaço midiático de interação em que são enunciados sentidos; uma moldura é,

\footnotetext{
${ }^{9}$ Esta capitalização, realizada ao tornar visível algo produzido em outro campo, é possível graças ao (quase) monopólio na "emissão" desta moeda visibilidade por parte das mídias privadas.
} 
em última análise, a condição objetiva de atualização de sentidos construídos midiaticamente $\left(\right.$ KUHN JUNIOR, 2008) ${ }^{10}$.

No âmbito das interfaces midiático-digitais, uma das principais marcas, em termos de uso, é o seu modo de acionamento, que é predominantemente disparado por sujeitos individuais nos limites do que está disponível, ou seja, programado pelos dispositivos técnicos de um portal de internet (KUHN JUNIOR, 2008). Assim, uma vez que os sujeitos provocam a sua imersão na tela do computador, e se deparam com molduras visuais (imagens dentro de imagens), define-se, a nosso ver, um processo intersemiótico gerador de experiências, em que a ação sígnica se produz e se reproduz nos usos possíveis que os indivíduos fazem dos produtos-serviços gerados nos ambiente virtual (no interior daquela moldura).

Esse mundo de experiências constitui-se de uma sobreposição de molduras (KILPP, 2003); há, portanto, sujeitos constituindo macromolduras, como é o caso do ambiente do próprio portal de internet (moldura-ambiente), que fornece tecnicamente as condições de acesso a diferentes modos de participação e interação. Os ambientes demarcados por essas macromolduras denominaremos de aparelho-provedor (KUHN JUNIOR, 2008), que, nesse estudo, corresponde ao Jornal NH Online, versão para web do Jornal NH, produto da empresa jornalística Grupo Sinos ${ }^{11}$.

Um aparelho-provedor disponibiliza aos sujeitos usuários o acesso àquilo que denominamos de programa-de-serviço, ou seja, um conjunto de molduras que demarcam espaços específicos de informação e interação do sujeito (noticias, um fórum, ou uma enquete, por exemplo) com aquilo que é programado no interior do aparelho-provedor (portal de notícias de uma mídia privada). Há, igualmente, milhares de sujeitos individuais objetivamente situados fora das macromolduras mas, ao se lançarem - no uso - para o seu interior, se constituem não apenas como usuários-consumidores de um programa-de-serviço,

\footnotetext{
${ }^{10}$ A noção de moldura, tal como entendida aqui, aproxima-se da noção de enquadramento (framing) de Erving GOFFMAN (2011), uma vez que ambas referem-se a demarcação de sentidos; no entanto, optamos por manter a noção de moldura, tal como desenvolvida em nossa tese de doutoramento, derivada dos estudos de Jacques Aumont sobre pintura e cinema (2004, p 112 - 114). Nessa perspectiva, além de sinalizar para conteúdos e processos de enquadramentos de sentidos, refere-se também às tecnicidades que compõem a própria moldura, como um componente da demarcação de sentido. Dito de outro modo, a moldura também opera na produção de sentido, em função das suas múltiplas formas, modelos e condições materiais de apresentação - formatos, texturas, cores, movimentos. (KUHN JR, 2008, p 55 - 59). Sobre a noção de enquadramento (framing) ver ainda: SANFELICE, G. R, 2015, v. 1, p. 33-52.

11 As macromolduras são as demarcadoras de identidade institucional que pode ser um ente público (como portais virtuais das prefeituras) ou um ente jurídico empresarial (portais de notícias de mídias privadas), ambos inscritos na lógica da produção de bens midiáticos e orientados por determinações, respectivamente, de ordem pública e mercantil.
} 
mas atuam como seus próprios produtores, ou seja, é o usuário-leitor que vai sobrepondo molduras, compondo e recompondo temporalidades e atualizando experiências de interação a partir de diferentes materiais acessados. Desse modo, esses sujeitos usuários e produtores podem estar recompondo modos de participação na vida pública das cidades, sendo que o acionamento dessas condições técnicas, moldurais, é mais que um simples meio de participar, é a própria condição da sua realização. Essa coleção de conteúdos digitais constituída a partir de múltiplos acionamentos sobrepostos, é que estaremos denominando de molduras de participação. O propósito, portanto, é analisar como tais molduras enquadram o sentido de participação no contexto das relações que se estabelecem entre distintos sujeitos sociais: o leitor cidadão, a mídia privada e a gestão pública.

A Moldura, portanto, será entendida aqui como uma tecnicidade que demarca ambiências de interação no interior das quais o sentido de participação se realiza. Importante para este estudo foi o reconhecimento dos processos de interação cuja dinâmica se caracteriza por sua construção contínua e contextualizada, que se desenvolve em virtude da negociação relacional durante o processo, onde cada ação retorna sobre a relação, movendo e transformando tanto o próprio relacionamento quanto os interagentes (impactados por ela). Esse caráter de coordenação recíproca (reciprocidade de condutas ou causalidade mútua), identificado nos processos de interação, foi tipificado por Alex Primo como sendo interação MÚTUA e se opõe aos processos interativos baseados em uma cadeia linear, onde uma ação "A" causa necessariamente uma reação "R", como o clicar do botão salvar no Word, denominado por Primo de REATIVOS e estão na base dos modelos informacionais transmissionistas. $\left(2007\right.$, p.107 - 116). ${ }^{12}$

\section{O CONTEXTO EMPÍRICO: EMOLDURAMENTOS DE AMBIENTES DE PARTICIPAÇÃO NO NH ONLINE.}

Tomamos como base um estudo preliminar da totalidade dos jornais online ativos de empresas jornalísticas sediadas no Estado do Rio Grande do Sul. De uma lista com de 95

\footnotetext{
12 Primo desenvolve essa tipologia a partir de uma reflexão sobre a palavra interação e sobre o seu desenvolvimento ao longo da história das mídias, desde a TV até a interação mediada por computador. Dentre os autores estudados por Alex Primo (2007), destacamos: André Lemos (2003); Enzensberger (1978); Machado (1997); Andrew Lippman; Rafaeli (1998); Jensen (1999); Marcos Silva (2000), in PRIMO, 2007. Convém destacar, ainda, que ao adotarmos à noção de interação mútua, nos baseamos na sua condição de tipo ideal, ou seja, nos apoiamos em sua força explicativa, problematizadora e não na sua força descritiva; nesse sentido, como recurso teórico-metodologico, visa tão somente orientar nosso olhar para a compreensão da realidade e não assume o lugar da realidade em si.
} 
sites $^{13}$ identificamos que os recursos recorrentes na maioria dos jornais para instaurar a participação do leitor estão fundados na possibilidade de comentar ou enviar matérias, notícias ou opiniões através de molduras como, por exemplo: "carta do leitor", "fale conosco","formulários para contato", "comente a notícia", "envie sua notícia”, "fala leitor", "fórum do leitor", "você repórter".

Com base no princípio teórico de existência de demarcadores de ambiências exclusivas de interação, fundadas em molduras específicas que estamos denominado de molduras de interação, é que identificamos os jornais Zero Hora e Jornal NH como aqueles que potencialmente se aproximam da noção ideal de interatividade mútua. No caso do Jornal Zero Hora, temos as molduras "Participe" e o "Leitor-repórter"; no caso do Jornal NH temos a moldura "Interativo - cidadão-repórter"

Como ilustração analítica, optamos por detalhar o caso do "Interativo - cidadãorepórter", entendido aqui como um programa-de-serviço disponibilizado para acesso ao usuário-leitor desde o interior das macromulduras do Jornal NH Online ${ }^{15}$.

O NH Online é a versão para web do Jornal $\mathrm{NH}^{16}$, o mesmo que é editado em versão impressa; cabe mencionar, desde já, que os mesmo conteúdos do "Interativo - cidadão -

\footnotetext{
${ }^{13}$ A última verificação sobre a disponibilidade de acesso a esses jornais online foi realizada durante o mês de maio de 2012. Para listagem completa dos jornais online ativos, de empresas jornalísticas sediadas no Estado do Rio Grande do Sul, em 2012, acessar http://www.guiademidia.com.br/jornaisdoriograndedosul.htm /

${ }^{14}$ Em outros casos, como o jornal Correio do Povo e o jornal O Sul, identificamos espaço para envio e publicação de opinião dos leitores, através dos blogs dos seus jornalistas ou colunistas, no entanto, para esse estudo, tais espaços não serão tomados como objeto, já que estamos entendendo os blogs como um aparelho independente da macromoldura dos Jornal citados, ou seja, os blogs não se constituem como molduras de interatividade gerada especificamente no interior de uma dada macromoldura.

${ }^{15}$ A escolha por abordar aqui apenas o caso do Jornal NH Online está associada ao nosso entendimento de que o tratamento dispensado às questões ligadas aos modos de organizar a vida cotidiana de pequenas e médias cidades, encontra-se mais intensamente respaldada em produtos midiáticos cuja agenda é predominantemente legitimada pelos temas de abrangência local, "da comunidade", enquanto que um jornal de circulação estadual (como o jornal Zero Hora, por exemplo) as pautas estão relacionadas a temas demasiados abrangentes e de modo geral distantes do pequenos assuntos (das pautas) da comunidade local; dito de outro modo, essa adequação de tamanhos entre as agendas da cidade e a agenda do jornal é geradora de uma ambiência de onde emergem condições de estudo próximas ao que metodologicamente podemos considerar como um tipo ideal.

${ }^{16} \mathrm{O}$ Jornal NH é um dos principais produtos da empresa jornalística Grupo Sinos e tem sua sede em Novo Hamburgo, RS. Teve seu início em torno de um pequeno folheto quinzenal em 1957 e é hoje abrange serviços da área da comunicação; são produtos da empresa Grupo Editorial Sinos: Jornais VS, NH, Diário de Canoas, Diário de Caxias, Rádio ABC, Portal de Internet. (GRUPO SINOS, 2012) Apresenta-se destacando como sendo a sua mais importante característica a "busca pela valorização da comunidade em que está inserida" e por estar "comprometido com seus leitores para divulgar os mais diversos fatos, e busca constantemente a participação comunitária" (GRUPO SINOS, 2012). O seu principal jornal, o Jornal NH, é o quarto jornal mais lido do estado (os três primeiros são, Zero Hora, Correio do Povo, e Diário Gaúcho) e, em nível nacional, também é destaque por ser o maior jornal do país em número de assinaturas fora de capitais. O jornal NH é atualmente o principal negócio do Grupo Editorial Sinos, traz a missão do grupo, de promover o desenvolvimento das comunidades e região. (GRUPO SINOS, 2012).
} 
repórter" são publicados tanto na versão digital, quanto na seção "Interativo" da versão impressa do Jornal.

Figura 1 - A macromoldura do NH Online e os seus componentes moldurais

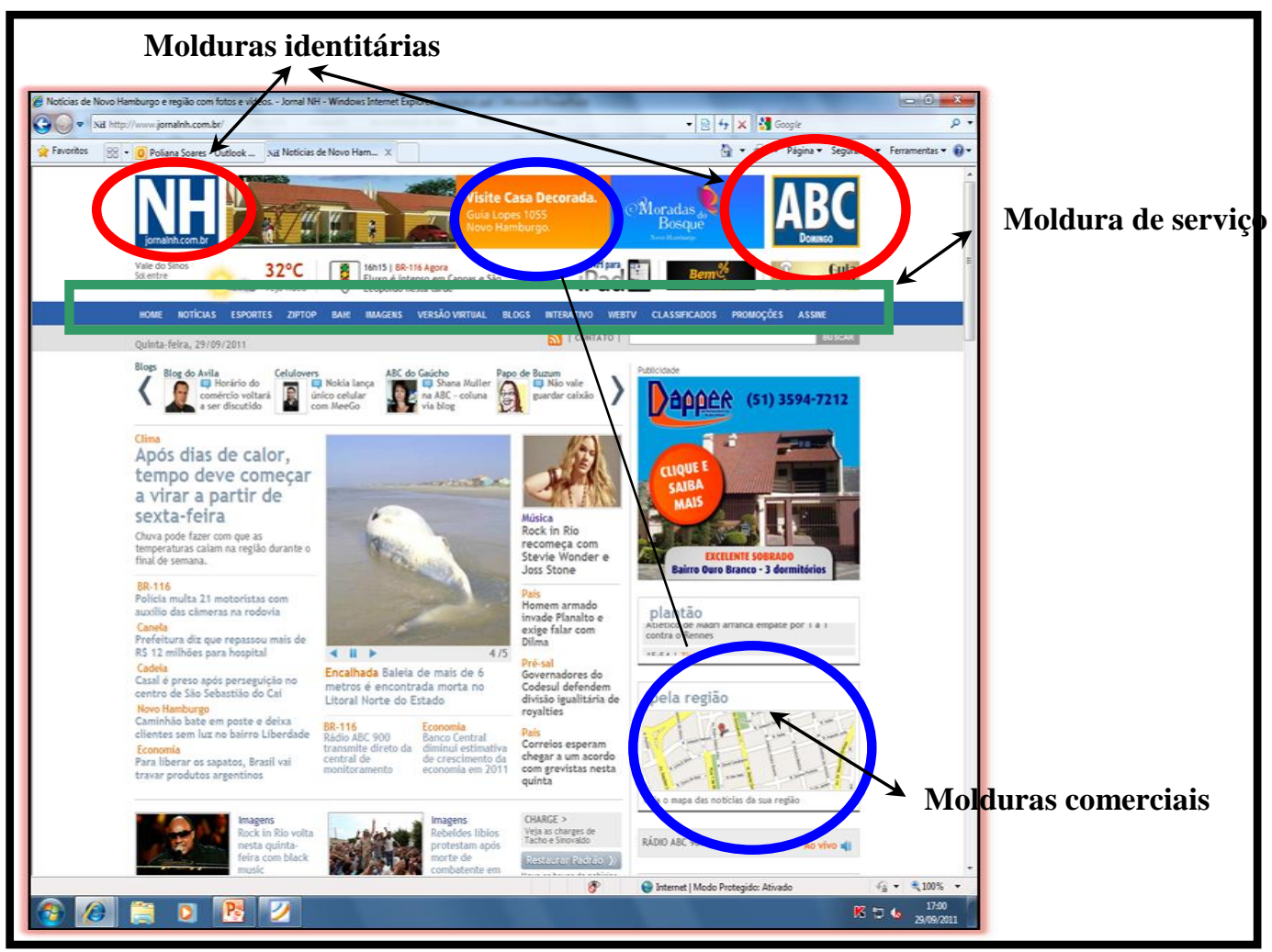

Fonte: recorte de tela realizado pelos autores a partir do web site do Jornal NH

Quanto aos componentes moldurais constitutivos dessa macromoldura (ver figura 1, acima), destacamos a) as macromolduras identitárias, tais como ícones de identificação e marca de propriedade presentes na parte superior da página; b) o índice (menu) de programa de serviços e conteúdos e c) as molduras externas comerciais.

\subsection{O programa de serviço "interativo - cidadão-repórter"}

Em sua dimensão macroestrutural O Jornal NH online opera como "aparelhoprovedor", desde onde o usuário-leitor poderá acionar as molduras de participação que fundam o programa-de-serviço denominado de "Interativo".

Bem-vindo ao Meu NH Interativo, um espaço onde você — cidadão-repórter - poderá compartilhar suas histórias através de textos, imagens e sons, interagindo com seus vizinhos e amigos da comunidade. Dê sua opinião, reconhecendo o que é bom, alertando sobre o que poderia melhorar em nossa região. PARTICIPE!! Clique aqui e saiba mais (JORNAL NH. Interativo. Disponível em: 〈www.jornalnh.com.br/interativo> Acesso em: 25 abr. 2012). 
As Figuras 2 e 3 (abaixo) reproduzem as molduras que atuam na demarcação visual dessas ambiências de participação na vida da comunidade:

Figura 2 - Moldura de acesso ao Programa de serviço INTERATIVO

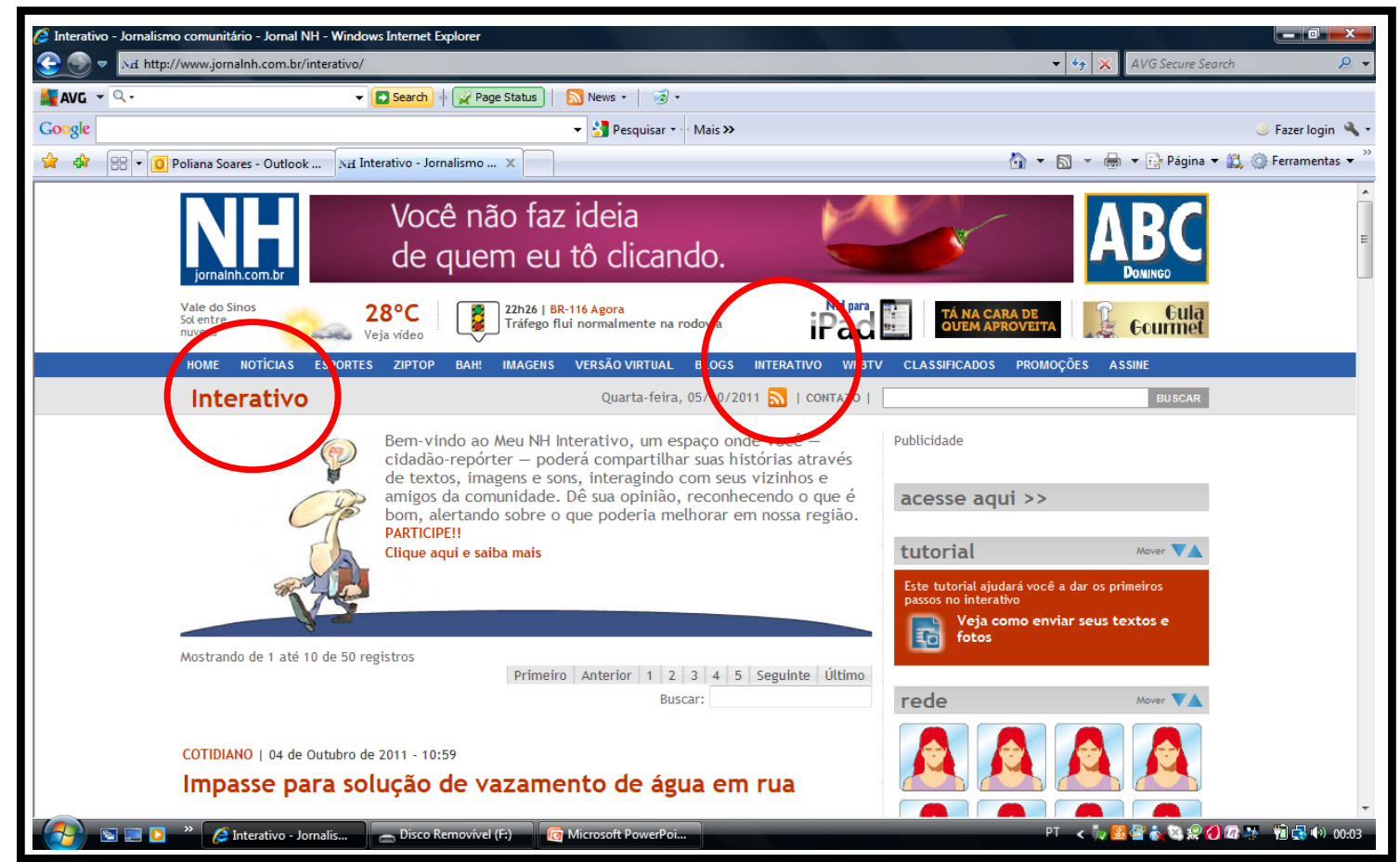

Fonte: recorte de tela realizado pelos autores a partir do web site do Jornal NH.

Dito modo resumido, os processos interativo em análise ocorrem da seguinte forma: qualquer leitor do Jornal (em sua versão impressa ou digital) encaminha uma demanda (pergunta, opinião, reclamação) para o jornal; esse encaminhamento ocorre tanto através da interface do Interativo, ou através de email ou ainda através de ligação telefônica para redação do jornal; o Jornal, por sua vez, emoldura a demanda publicando-a no Interativo e encaminha a demanda aos destinatários (em geral, órgãos públicos); no prazo de até 72 horas uma resposta será publicada no Interativo. Sempre será publicada uma resposta, seja essa resposta a do órgão público acionado pela demanda ou da redação do jornal, e, dependendo da negociação relacional estabelecida no processo pelos interagentes, estes podem participar de futuras problematizações, podendo o processo ser encerrado ou não.

Quanto ao processo, no que diz respeito ao acionamento dessa moldura específica, temos o seguinte fluxo: desde o menu de opções (molduras de serviço) que compõe o índice de programas, serviços e assuntos na parte superior e/ou inferior da macromoldura do $\mathrm{NH}$ Online (Figura 1 e Figura 2, acima), o usuário acessa pela palavra Interativo e é direcionado 
para o interior dessa moldura de serviço, onde receberá instruções sobre como proceder para $\operatorname{participar}^{17}$.

O cadastramento ${ }^{18}$ compõe a chave de acesso a esse programa-de-serviço, ou seja, para se tornar habilitado a acionar a moldura de participação, é preciso disponibilizar à empresa uma série de dados e informações de identificação pessoal; somente a partir do cadastramento é que são geradas as condições de processos interação. O cadastro, como condição de acionamento, define regras de publicação ${ }^{19}$ que precisam ser necessariamente aceitas pelo usuário, submetendo-o à termos e condições, que determina amplos poderes ao jornal na manutenção do fluxo das informações. O usuário cadastrado é responsabilizado juridicamente pelo conteúdo, mas o jornal faz a moderação do conteúdo, podendo excluir, bem como divulgar todo ou parte do conteúdo disponibilizado pelo usuário em função dos seus critérios jornalísticos e publicitários.

17 No interior dessa moldura, estão os títulos e resumos dos Post's que podem ser acessados para leitura independente do cadastramento. Através dos links "Clique aqui" e "saiba mais", ou "participe!", aciona-se o acesso à Central do Internauta, desde onde realiza-se o cadastro, e posteriormente, o login de acesso, ou seja, para que o usuário-leitor possa publicar sua opinião ele deverá acionar a moldura de participação Interativo, e identificar-se para o jornal através do preenchimento de um contrato (resumido na nota 19). Essa moldura interna "cadastro" é composta por cinco formulários denominados por: Acesso; Dados Pessoais (o cadastro em si, inclusive com assinatura das condições do Termo de uso); Perfil; Foto e Logoff, que após preenchidos, o usuário-leitor já está autorizado para publicar suas postagens após a mediação do jornal. Esse cadastro, por sua vez, permite também acesso a outras áreas do site do Jornal NH.

${ }^{18}$ Para os usuários já cadastrados que querem participar postando sua opinião, o acesso é pelo mesmo caminho por onde se realizam os cadastros, porém, o link “Acesse aqui" é o principal e redireciona o usuário-leitor para o local de login com o seu email e senha. Os cinco formulários que aparecem no momento do primeiro cadastro no Interativo compõem o ambiente individual dos internautas, e é através do formulário "Acesso" que o usuário pode entrar na moldura Interativo, selecionar a opção "Escrever" e então abre uma caixa de texto onde se pode redigir os posts para posterior publicação.

${ }^{19}$ Regras de publicação de conteúdo no interativo: o jornal removerá deste site qualquer comentário que não respeite as seguintes regras: 1. Mantenha a postura - Este é um fórum público, aberto a pessoas civilizadas que não apreciam linguagem obscena, vulgar ou sexual, mesmo que seja criativa. 2. Mantenha a civilidade - Não difame, ameace, abuse ou invada a privacidade de outros leitores ou os conteúdos das matérias. Nenhum tipo de preconceito será tolerado. 3. Mantenha a verdade ideológica e a legalidade - Não minta, não tome a identidade de outro indivíduo e não poste comentários que defendam qualquer tipo de atividade ilegal. 4. Seja coerente Mantenha-se em sintonia com o assunto tratado na matéria. Não poste propagandas ou solicitações para fundos, bens, serviços ou partidos políticos. 5. Seja responsável - Comentários são de estrita responsabilidade daqueles que os postam. 6. Divida o seu conhecimento - Dê-nos sua contribuição, sua experiência e opinião. Se você visualizar qualquer erro em uma matéria ou acreditar que haja assuntos que mereçam ser mais detalhados, mande e-mail para redacaomultimidia@gruposinos.com.br ou ligue para (51) 3594 0403. 7. Exerça sua autoridade Policie os comentários e sugira a remoção daqueles que violam as regras do site. 8. E lembre-se - Violadores das regras poderão ser permanentemente banidos de escrever comentários.Dúvidas sobre comentários ou outros tipos de perguntas sobre este site podem ser enviadas para redacaomultimidia@gruposinos.com.br. JORNAL NH. Interativo. Termo de uso. Disponível em:http://www.jornalnh.com.br/central/cadastro>Acesso em: 25 abr. 2012. 
Figura 3 - Exemplo de Emolduramentos de ambientes de participação NH Online

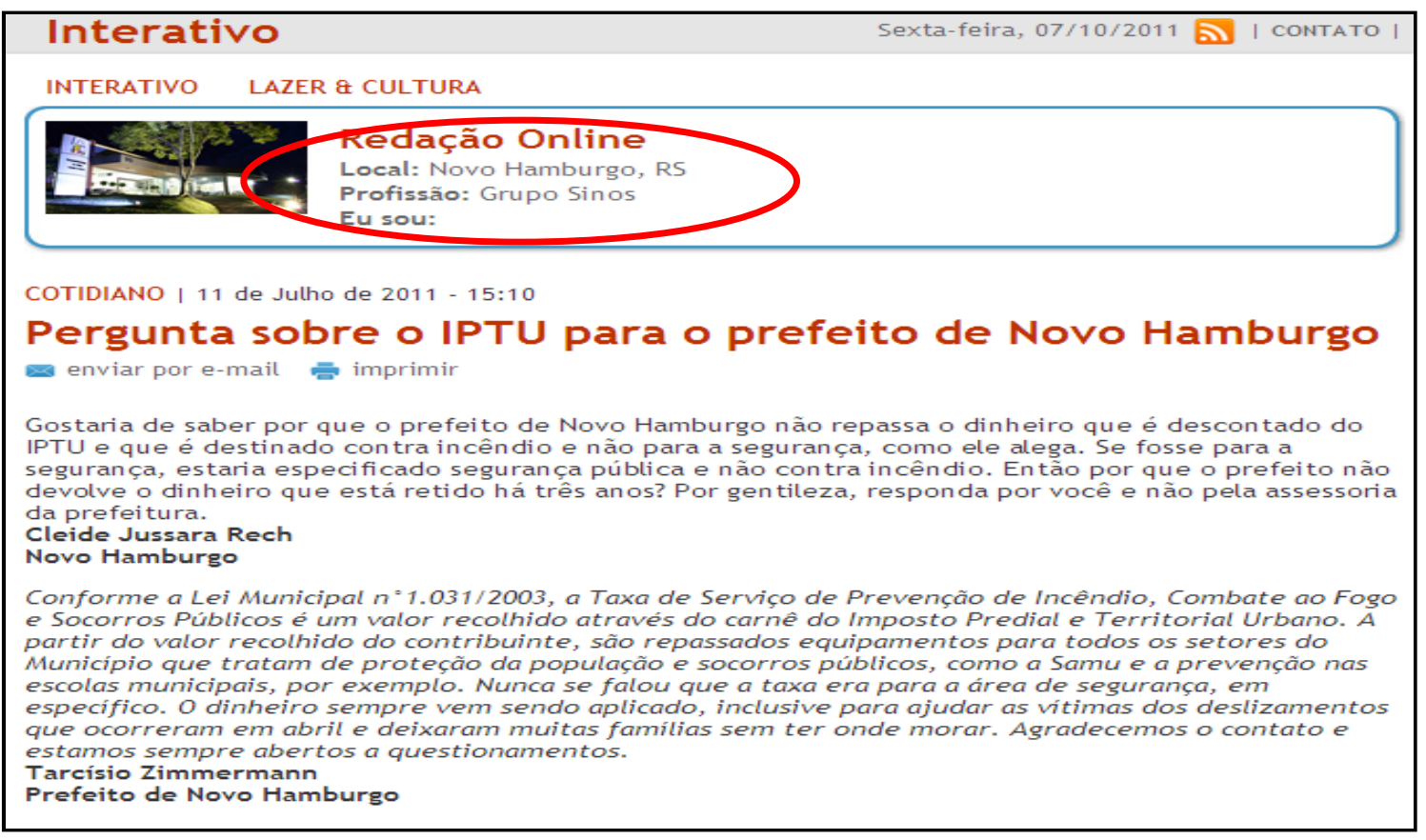

Fonte: recorte de tela realizado pelos autores a partir do web site do Jornal NH.

Somente a partir do cadastro, o usuário poderá acionar as molduras de interatividade dando visibilidade a sua fala; o que significa dizer que a sua participação na vida da comunidade, para se realizar, depende da mediação do jornal - de uma alquimia simbólica (BOURDIEU, 1996) - que transforma sua fala em um post ${ }^{20}$, ou seja, em um bem-produto simbólico de propriedade do Jornal, um produto-participação. Na figura 3 (acima), podemos observar um exemplo de emolduramento desse produto.

Durante o período de abril de 2011 até abril de 2012 o "Interativo - cidadão-repórter" foi acompanhado diariamente; desse controle, criamos uma memória das opiniões, reclamações, dúvidas e outras demandas que foram enviadas e publicadas nessa moldura; convertidas em unidades de análise totalizaram um acervo de 1.427 unidades.

Essas unidades foram analisadas individualmente; buscamos, assim, identificar os sujeitos e os conteúdos implicados na interação. Organizamos os dados considerando: 1) a tecnicidade do acionamento; 2) os destinatários e 3) os conteúdos temáticos.

Quanto ao modo de acionamento (Quadro 1, abaixo), verificamos duas modalidades de acionamento da moldura de participação: a indireta (operada pela Redação do Jornal) e a direta (operada pelo usuário-leitor cadastrado). Verificamos que a maioria dos posts publicados no período estudado não é realizada exclusivamente através do acionamento direto

${ }^{20}$ Post é no nome atribuído pelo jornal às postagens feitas pelos usuários-leitores na moldura Interativo. 
de um usuário-leitor cadastrado no Interativo, ou seja, os conteúdos também foram postados pela própria REDAÇÃO do Jornal NH, o que quer dizer que não é preciso estar inserido em uma cultura digital (SANTAELA, 2003) para participar no Interativo; as pessoas podem se dirigir à redação do Jornal por telefone, email, cartas, e a Redação encarrega-se de acionar as molduras digitais fundando a participação, nesse caso o conteúdo da participação é publicado com a assinatura "Da Redação": temos aqui o caso de uma participação indireta onde o leitor usa as molduras digitais, mas acessa a redação do jornal, e é esse quem usa o espaço propriamente emoldurado para efetivar a participação do usuário-leitor ${ }^{21}$.

Quanto aos destinatários dessas participações (Tabela 1, abaixo), ou seja, a quem se direciona o conteúdo dos produtos-participação, temos, em sua quase totalidade, os órgãos públicos municipais e, em especial, à Prefeitura Municipal. Das postagens direcionadas a esse destinatário, em geral, todas foram respondidas e a maioria assinada pela assessoria de imprensa da Prefeitura Municipal de Novo Hamburgo.

Tabela 1 - Postagens e destinatários

\begin{tabular}{|l|c|l|c|}
\hline \multicolumn{1}{|c|}{ A } & Postagem & \multicolumn{1}{c|}{ B } & Destinatários \\
\hline Usuário & 207 & Prefeituras e Orgãos & 1040 \\
\hline Redação & 1220 & Outros Destinatários & 387 \\
\hline Total A & 1427 & Total B & 1427 \\
\hline
\end{tabular}

Fonte: Elaborado pelos autores

As 207 postagens feitas pelos próprios usuários, são feitas através do login individual. As 1220 postagens feitas pelo Jornal NH (Redação Online) são advindas da comunidade através de emails, telefone e pessoalmente. As 1040 postagens que tiveram como destinatária a prefeitura, também abrangem secretarias de saúde e hospitais públicos; assuntos políticos envolvendo personalidades; serviços de abastecimento de água e saneamento; e em menor escala serviços de policiamento e guarda municipal ${ }^{22}$.

Nesse caso, o Interativo converte-se apenas em "meio" de divulgação e visibilização de uma participação inexistente? Entendemos que não: o indivíduo, ao se direcionar para o interior do campo jornalístico, aciona processos (mesmo que a tecnicidade desses processos

\footnotetext{
${ }^{21}$ Essa é a estratégia adotada pelo Jornal para dar sustentabilidade a esse programa-de-serviço online, apontando que o número de usuários cadastrados, que poderiam acessar diretamente o interativo e dar sustentabilidade a esse produto baseado apenas nos dispositivos de interatividade digital, é insuficiente.

22 As 387 postagens que tiveram como destinatário Outros, contemplam o serviço de energia elétrica; eventualmente outras empresas privadas e várias postagens sem um destinatário específico, onde o usuário manifesta a sua opinião sobre diversos temas o que acaba não gerando uma demanda de resposta.
} 
seja executada por uma instancia particular desse campo, no caso, a redação); esse uso se materializa efetivamente como produto-participação graças às molduras que geram a ambiência de interatividade; em última análise a operatividade das molduras é que realiza a participação e não o contato estabelecida anteriormente entre indivíduo e Redação do jornal por telefone, email, carta, etc. ${ }^{23}$

Poderíamos ainda problematizar a temporalidade do processo de interação. O que observamos é que os processos interativos emoldurados pelo Interativo não são sincrônicos, ou seja, a negociação entre os interagentes - usuário-leitor (cidadão)-redação-órgão público ocorre em uma "duração" que é limitada pelo Jornal ao prazo de 72h. Nesses termos, os modos de interação verificados nas molduras do Interativo os distancia do tipo puro Interação Mutua, na perspectiva de Primo, especialmente pelo caráter da temporalidade não sincrônica. Mas, conforme verificamos novas durações podem ser re-acionada de forma ilimitada. Assim novos fluxos de problematização podem ser acionado e reacionado, por qualquer uma das partes, especialmente pelo usuário-leitor (cidadão), a qualquer momento, mantendo assim o padrão de negociação em torno de algum tema-problema da vida da cidade.

Essa especificidade nos coloca a possibilidade de pensarmos essa interação como sendo mútua assíncrona. Graças ao tipo puro trazido por Primo é que foi possível identificar, na realidade observada, que os interagentes reúnem-se em torno de contínuas problematizações e estão envolvidos em um fluxo de problematização que motiva uma constante negociação. Temos a problematização indo e vindo, acionando negociação em torno de diversos temas do cotidiano da cidade. Cada ação expressa tem um impacto recursivo sobre a relação e sobre o comportamento dos interagentes. Isto é, o relacionamento entre os participantes vai definindo-se ao mesmo tempo em que acontecem os eventos interativos (...). (PRIMO, 2007. p.228).

Temos até aqui, independente dos conteúdos implicados na interatividade, que o acionamento (direto ou indireto) do programa-de-serviço "Interativo" pelo usuário-leitor, instaura a participação de indivíduos que se realizam como produto (em-uso) nos domínios dessa moldura, simultaneamente, tanto na condição de leitores-repórteres, uma vez que compõem conteúdo jornalístico, como na condição de cidadãos, uma vez que pautam temas na agenda pública, que é o que vamos ver agora, ao tratarmos dos destinatários do produtoparticipação.

\footnotetext{
${ }^{23}$ Cabe mencionar que os mesmos conteúdos são publicados tanto na versão digital quanto na seção do Interativo na versão impressa do Jornal, muito embora nesse caso possam vir a sofrer alterações na sua estrutura em função dos limites de espaço no layout da página do jornal.
} 
Para identificar os propósitos da interação consideramos a categorização proposta pela própria redação (Redação Online - Interativo - Jornal NH) responsável pelo desenvolvimento desse programa-de-serviço. A Redação distribuiu as postagens segundo seu propósito da interação, ou seja, "Elogios e ou Agradecimentos", "Opinião" e "Reclamações", como podemos observar na Tabela 2.

Tabela 2 - Distribuição das postagens segundo propósito da interação

\begin{tabular}{|l|r|}
\hline Elogios e ou Agradecimentos & 181 \\
\hline Opinião do Leitor & 272 \\
\hline Reclamações & 974 \\
\hline Total & $\mathbf{1 4 2 7}$ \\
\hline
\end{tabular}

Fonte: elaborado pelos autores

Com o propósito de identificar os temas abordados por cada um dos posts, tratamos de submetê-los a um processo de categorização, inspirado no método de análise de conteúdo de Bardin $(2004)^{24}$. Desse processo obtivemos a seguinte tabela de temas:

Tabela 3 - Os temas abordados pelos posts segundo seu propósito da interação.

\begin{tabular}{|l|c|c|c|c|}
\hline \multicolumn{1}{|c|}{ Temática do Jornal } & Total & $\begin{array}{c}\text { Elogios e/ou } \\
\text { Agradecimentos }\end{array}$ & Opinião do Leitor & Reclamações \\
\hline Agenda & 4 & 0 & 3 & 1 \\
\hline Agradecimento & 51 & 51 & 0 & 0 \\
\hline Antigamente & 56 & 1 & 51 & 4 \\
\hline Cidades & 137 & 4 & 2 & 131 \\
\hline Cidadania & 9 & 2 & 1 & 6 \\
\hline Colégio & 9 & 2 & 2 & 5 \\
\hline Correspondências & 2 & 0 & 0 & 2 \\
\hline Cotidiano & $\mathbf{8 0 8}$ & $\mathbf{1 0 9}$ & $\mathbf{1 0 8}$ & $\mathbf{5 9 1}$ \\
\hline Crônicas & 36 & 0 & 36 & 0 \\
\hline Denúncia & 9 & 0 & 2 & 7 \\
\hline Entulho & 3 & 0 & 0 & 3 \\
\hline Fotos & 9 & 3 & 0 & 6 \\
\hline Infiltração & 11 & 0 & 0 & 11 \\
\hline Opinião & 15 & 0 & 15 & 9 \\
\hline Perigo & 9 & 0 & 0 & 1 \\
\hline Pirataria & 1 & 0 & 0 & 0 \\
\hline Poemas & 24 & 0 & 24 & 74 \\
\hline Saúde & 54 & 10 & 0 & 35 \\
\hline Reclamação & 76 & 0 & 0 & 48 \\
\hline Outros & 52 & 0 & 17 & \\
\hline Trânsito & 52 & 1 & 3 & \\
\hline Total & $\mathbf{1 4 2 7}$ & & & \\
\hline & & & & \\
\hline
\end{tabular}

\footnotetext{
${ }^{24}$ Foram categorizados a partir do método de análise de conteúdo de BARDIN (2004), com apoio do software de análise qualitativa Nvivo. Para tanto, levamos em conta a classificação temática proposta pela redação do Interativo.
} 
Fonte: Elaborado pelos autores.

Dentre estes temas, o que recebeu destaque, por compor 808 postagens, foi o "Cotidiano". Com o propósito de identificar os temas agrupados pela redação do jornal em torno dessa noção abstrata de "cotidiano", tratamos de submetê-las a um segundo processo de categorização, do qual resultou a Tabela 4:

Tabela 4 - A distribuição dos temas das postagens considerando a categoria COTIDIANO pré-definida pelo jornal, segundo os três propósitos de interação (elogio, opinião, reclamação)

\begin{tabular}{|l|c|c|c|c|}
\hline \multicolumn{1}{|c|}{ Tema } & Total & $\begin{array}{c}\text { Elogios e/ou } \\
\text { Agradecimentos }\end{array}$ & Opinião do Leitor & Reclamação \\
\hline Energia Elétrica & 52 & 3 & 0 & 49 \\
\hline Limpeza Urbana & 95 & 0 & 0 & 95 \\
\hline Meio ambiente & 53 & 2 & 25 & 37 \\
\hline Outros & 84 & 20 & 25 & 15 \\
\hline Política Local & 64 & 24 & 1 & 115 \\
\hline Saneamento & 119 & 3 & 6 & 80 \\
\hline Saúde & 117 & 31 & 3 & 19 \\
\hline $\begin{array}{l}\text { Segurança e } \\
\text { Policiamento }\end{array}$ & 24 & 2 & 15 & 0 \\
\hline $\begin{array}{l}\text { Trânsito e } \\
\text { Mobilidade }\end{array}$ & 159 & 2 & 14 & 0 \\
\hline Eventos & 34 & 20 & $\mathbf{1 1 0}$ & $\mathbf{5 9 1}$ \\
\hline Esporte & 7 & 0 & $\mathbf{1 0 7}$ & \\
\hline Total & $\mathbf{8 0 8}$ & & & 142 \\
\hline
\end{tabular}

Fonte: elaborado pelos autores

Nosso objetivo, nesse momento do estudo, não foi desenvolver uma problematização de tais conteúdos no contexto das tramas sociais locais e sua vinculações com processos comunicacionais; tratamos apenas de realizar tal levantamento temático com o intuido de identificar os conteúdos predominantes, significados nos domínios desses emolduramentos midiáticos (nesse caso, pelo Interativo). A partir desse levantamento - que pôde ser observado no quadro acima - foi possível verificar que os temas de maior incidência estão relacionados à temáticas do cotidiana da vida da cidade. Correspondem, portanto, aos conteúdos que vem ocupando lugar na agenda das políticas públicas em áreas metropolitanas. ${ }^{25}$

\footnotetext{
${ }^{25}$ Everton Rodrigo Santos, em outra pesquisa, sobre Capital Social e Políticas Públicas na Região Metropolitana de Porto Alegre, nos traz dados preliminares sobre percepção do cidadão sobre as diferentes áreas de atuação da gestão pública em Novo Hamburgo; a pesquisa aponta que dentre as áreas de maior fragilidade, são a saúde, segurança pública, temas esses que igualmente aparecem citados com grande frequência no Interativo. (http://www.jornalnh.com.br/novo-hamburgo/395544/moradores-querem-mais-seguranca-e-saude-na-cidadeveja-video.html)
} 


\section{CONSIDERAÇÕES}

Consideramos o caso do Jornal NH online como caso emblemático de emolduramento de espaços de interação mútua no jornalismo online do RS e destacamos a força dessas molduras na geração de sentidos de participação: o que percebemos é que através desse processo de emolduramento - que é o Interativo - diferentes sujeitos (o jornal, o cidadão e o gestor público) se afirmam enquanto tais à medida em que realizam tal efeito de participação na vida da cidade. Ao identificarmos os sujeitos e conteúdos que atuam no interior das molduras do interativo, percebemos que a interação, do tipo mútua, gera um "efeito de participação" que resulta muito mais como um produto simbólico comercializado pelo jornal do que em função do seu conteúdo propriamente dito.

O fato das postagens direcionadas a Prefeitura Municipal terem sido sempre respondidas por ela pode, não apenas indicar o reconhecimento do Interativo como meio de encaminhar respostas às demandas e questionamentos dos cidadãos sobre a vida pública, mas aponta para o reconhecimento do Interativo como moldura capaz de gerar, em cada resposta reenviada ao jornal, as próprias condições de realização de um produto simbólico que se apresenta como participação cidadã e que adquire cada vez mais valor no campo político. A análise dessas molduras nos permitiu o reconhecimento dos efeitos desses post como produtoparticipação e o quanto eles se realizam, tanto do ponto de vista da geração de matéria jornalística (como produto jornalístico) quanto de geração de efeito político (produto político) ambos impactando sobre a gestão da vida pública (como produto político participação).

Nosso propósito não foi "medir" níveis de interação, uma vez que não se trata inferir estatisticamente sobre uma densidade de interação (se baixa ou alta) - já que a média de operações no período não passa de 4 participações por dia. Ao verificarmos os modos de conformação das moldura de interação nos interessou, sim, os modos como essa tecnicidade demarca ambiências de interação (PRIMO, 2007) no interior das quais o sentido de participação se realiza, no mesmo produto, como bem jornalístico e político.

Tais modos demonstram teoricamente a operatividade do efeito de intrusão analisado por Bourdieu, onde a lógica do mercado comunicacional (a lógica da empresa) se mescla à lógica política na composição e fortalecimento do valor participação como capital político para a gestão pública da cidade e como bem/produto comunicacional que, associado à marca 
identitária do Jornal, fortalece seus vínculos com o seu lugar (comunidade) onde realiza seus negócios como empresa privada.

Tanto o Jornal, o cidadão, quanto o gestor público (no âmbito da prefeitura) se realizam através de suas molduras (independente dos conteúdos) que são o começo e o fim de um lugar que estas demarcam um produto em uso (que é a participação) que permite a realização de todas essas condições:

1) para o jornal, porque gera e faz circular matéria jornalística (através de molduras específicas) que o fortalece no mercado comunicacional, ou seja, o acionamento da moldura de interação intensifica o seu uso, fazendo circular o próprio jornal; tais molduras objetivam o seu discurso social (presente nos seus mitos fundantes) e fortalecem a circulação de um produto ("o Interativo") afinado às qualidades da "participação cidadã", algo positivo em uma sociedade democrática. Assim, para a empresa midiática, a força e o valor de tais molduras não está tanto no conteúdo em si, posto em circulação (vimos que estes conteúdos são os mais diversos), mas na própria circulação de uma moldura como um produto. Nesse caso, a circulação da moldura-produto "interação" (e seu potencial uso) é que adquire significância (mais que os conteúdos postos em circulação). A moldura demarca então o acesso ao produto que depende do fortalecimento de um senso, uma qualidade positivada, que é o efeito interação/participação;

2) para os usuários-leitores, esses se realizam na objetividade da visibilização da sua fala; nesse caso a circulação do jornal é igualmente intensificadora de um senso positividade da sua participação no âmbito dos debates públicos;

3) enfim, para o gestor público que, ao interagir compondo as respostas às demandas encaminhadas, realiza nesse ato o efeito de participação que o fortalece como ente público.

Temos, então, que participação é emoldurada como produto em uso. Gerada no interior das tecnicidades midiáticas, que aqui denominamos de molduras de interatividades, essa participação-produto (por mais diferentes sentidos que a noção de participação pode vir a ter) realiza uma nova modalidade de ágora, ou seja, realiza um lugar de circulação de sentidos na intersecção dos campos midiático e político que acabam por afetar a política da vida.

Essa pesquisa aponta para o reconhecimento da moldura Interativo como espaço onde o sentido de participação do sujeito realiza-se, tanto na orientação das demandas da comunidade, quanto pautando assuntos ao jornal e à prefeitura, gerando significados e consequências diretas e indiretas nas administrações públicas. Esse fato aponta para a relevância dos estudos sobre o papel das mídias privadas na visibilização de temas ligados a 
vida da cidade e sua relação com a gestão pública e isso através do emolduramento de produtos e bens simbólicos aportados na positividade das noções políticas de participação, democracia, cidadania, inclusão social.

\section{REFERÊNCIAS}

AUMONT, Jacques. O olho interminável [cinema e pintura]. São Paulo: Cosasc \& Naiify, 2004.

BARDIN, Laurence. Análise de conteúdo. 3. ed. Lisboa, Portugal: Edições 70, 2004.

BAUMAN, Zygmunt. Modernidade líquida. Rio de Janeiro: Jorge Zahar, 2001.

La sociedad sitiada. Buenos Aires: Fondo de Cultura Económica de

Argentina, 2004.

BOURDIEU, Pierre. Razões Práticas - sobre a teoria da ação. São Paulo: Papirus, 1996.

Sobre a televisão. Rio de Janeiro: Zahar, 1997.

CANCLINI, Nestor Garcia. Consumidores e Cidadãos. Conflitos multiculturais da globalização. 4.Ed. Rio de Janeiro: Editora UFRJ, 1999. p 75-94.

CASTELLS, Manuel. A sociedade em rede. São Paulo: Paz e Terra, 1999.

GIDDENS, Anthony. As consequências da modernidade. 2.ed. São Paulo: Unesp, 1991.

GOFFMAN, Erving. Os quadros da experiência social. Petrópolis: Vozes, 2011.

GOVERNO FEDERAL. Histórico do governo Eletrônico. Disponível em:

<http://www.governoeletronico.gov.br/o-gov.br/historico> Acesso em: 29 mai. 2012.

. Ministério das cidades. Disponível em:

<http://www.cidades.gov.br/ministerio-das-cidades.> Acesso em: 03 jun. 2010.

Portal da Transparência do Governo federal. Disponível em:

<http://www3.transparencia.gov.br/TransparenciaPublica/sobre/quadroComparativo.html> Acesso em: 28 mai. 2012.

Informativo do Plano Diretor Participativo No 5. Brasil. 2006.

Disponível em: <http://www.cidades.gov.br/secretarias-nacionais/saneamento-

ambiental/acoes/plansab/anexos-subsidios-1/Anexo\%2010\%20\%20PDP.pdf.> Acesso em: 09 jun. 2010.

GRUPO SINOS. História do Grupo Sinos. 2012. Disponível

em:<http://www.gruposinos.com.br/historia.asp> Acesso em: 25 abr. 2012. 
IANNI, Octavio. A era do globalismo. 7.ed. Rio de Janeiro: Civilização Brasileira, 2002.

O Príncipe eletrônico. In: Enigmas da Modernidade. Rio de Janeiro:

Civilização Brasileira, 2001. p.141-166.

JORNAL NH ONLINE. Interativo. Termo de uso. Novo Hamburgo. 2012. Disponível em: <http://www.jornalnh.com.br/central/cadastro> Acesso em: 25 abr. 2012.

JORNAL NH ONLINE. Da redação. Universidade Feevale divulga pesquisa sobre Políticas Públicas. Novo Hamburgo, Segunda-feira, 11/06/2012. Disponível em <http://www.jornalnh.com.br/novo-hamburgo/395544/moradores-querem-mais-seguranca-esaude-na-cidade-veja-video.html> Acesso em: 26 de nov. 2012.

KILPP, Suzana. Ethicidades televisivas. São Leopoldo: Unisinos, 2003.

KUHN JÚNIOR, Norberto. Painéis fotográficos na internet: um estudo sobre os fotoblogs como molduras de mostração . 2008. 174 f. Tese Doutorado em Comunicação.

Universidade do Vale do Rio dos Sinos, São Leopoldo.

LYON, David. Intimidad, poder, persnoas. In: El ojo eletrónico. Madrid: Alianza Editorial, 1995.

PANERAI, Margarete A. E-Gov e a Participação popular. Disponível em:

<http://www.intercom.org.br/papers/nacionais/2009/resumos/R4-1717-1.pdf> Acesso em: 29 mai. 2012.

PRIMO, Alex. Interação mediada por computador: comunicação, cibercultura, cognição. Porto Alegre: Sulina, 2007.

RAICHELIS, Raquel. Gestão pública e a questão social na grande cidade. Lua Nova Revista de cultura e política, n. 69, 2006 p.13 -48. Disponível em: <http://books.google.com/books?id=EYbGeFN9dY0C\&pg=PT6\&dq=questao+social\&as_pt= MAGAZINES\&hl=es\&cd=9\#v=onepage\&q\&f=false >. Acesso em: 09 jun. 2010.

SANFELICE, G. R.. Enquadramento: origens, principais influências e usos do conceito. In: PIRES, G.L.; LISBÔA, M.M. (Org.). Quem será. 1ed. Florianópolis: Tribo da Ilha, 2015, v. 1, p. 33-52.

SANTAELLA, Lucia. Culturas e artes do pós-humano: da cultura das mídias à cibercultura. São Paulo: Paulus, 2003.

SILVERTONE, Roger. Porque estudar mídia? São Paulo: Loyola, 2002.

ULTRAMARI, C.; REZENDE, D. A. Planejamento estratégico e planos diretores

municipais: referenciais e bases de aplicação. RAC, Curitiba, v. 12, n. 3, p. 717-739. 2008.

VAZ, José Carlos. Internet e promoção da cidadania: a contribuição dos portais municipais. São Paulo: Ed. Blucher Acadêmico, 2007.

VERÓN, Eliseo La semiosis social. Fragmentos de una teoria de la discursividad, Barcelona: Gedisa, 1996. [parte I: Fundaciones (1975)]. 
Original recebido em: 22/01/2014

Aceito para publicação em: 06/12/2014

Norberto Kuhn Júnior

É graduado em Ciências Sociais e Doutor em Ciências da Comunicação pela Universidade do Vale do Rio dos Sinos (2008). Atualmente é professor-pesquisador da Universidade Feevale, no Programa de Pós-graduação em Diversidade Cultural e Inclusão Social e no Mestrado Profissional em Industria Criativa. Integra a linha de pesquisa em Políticas Públicas e Inclusão Social.

Everton Rodrigo Santos

É graduado em Ciências Sociais, Pós-Doutor Ciências Políticas pela Universidade Federal do Rio Grande do Sul - UFRGS - (2013). Professor-pesquisador do Programa de Pós-graduação em Diversidade Cultural e Inclusão Social da Universidade FEEVALE, Linhas de pesquisa: Inclusão social e políticas públicas.

Esta obra está licenciada sob uma Licença Creative Commons 